\title{
INFERÊNCIA AO USO DE IMAGENS LANDSAT5/TM PARA A ELABORAÇÃO DO PLANEJAMENTO NA BACIA HIDROGRÁFICA CÓRREGO DA VÉSTIA, SELVÍRIA-MS.
}

Adalto Moreira Braz ${ }^{2}$

\author{
Patricia Helena Mirandola Garcia ${ }^{3}$
}

\section{RESUMO}

Pode-se afirmar que o crescimento econômico sempre prevaleceu perante a utilização dos recursos naturais. Apesar de limitados, são esses recursos os indispensáveis para abastecer o mercado cada vez mais exigente, retirando cada vez mais matéria prima para a utilização em um processo produtivo nos moldes capitalistas. Como consequência, os recursos tornam-se escassos e o meio natural sente seu impacto de forma direta, afetando a biodiversidade ali existente. $O$ presente trabalho procura analisar a situação em que se encontra o Córrego da Véstia, localizada no município de Selvíria-Ms, a partir de análise descritiva da paisagem e compará-las com informações provenientes do satélite LANDSAT5/TM, para que assim possa concluir a confiabilidade das técnicas foto interpretativas. A partir da catalogação de ambos os dados, o que foi constatado é que a descrição a partir de imagens orbitais pode servir de auxílio para trabalhos de campo, mas não supre as necessidades da descrição e análise do mesmo. Trabalhando de forma isolada, percebe-se que a espacialização das imagens nos permite trabalhar em conjunto da paisagem, analisando os elementos que interagem na bacia, mas foi só a partir do trabalho de campo em que a descrição detalhada pode ocorrer.

PALAVRAS-CHAVE: Bacia Hidrográfica. Planejamento. Imagem de Satélite.

\section{INFERENCE TO USE IMAGES LANDSAT 5 / TM FOR PLANNING PREPARATION IN BASIN STREAM DRESSED, SELVÍRIA-MS.}

\section{ABSTRACT}

\footnotetext{
${ }^{1}$ Mestrando do PPGEO - UFMS/CPTL - thdeandrade@gmail.com

${ }^{2}$ Graduando em Geografia (Bacharelado) pela UFMS/CPTL - adaltobraz.geografia@gmail.com

${ }^{3}$ Prof. Dra ${ }^{a}$. do PPGEO - UFMS/CPTL - patriciaufmsgeografia@gmail.com
} 
It can be said that economic growth has always prevailed before the use of natural resources. Although limited, these are the necessary resources to supply the increasingly demanding market, taking more and more raw material for use in a production process in capitalist lines. As a result, the resources become scarce and the natural environment feel its impact directly affecting the biodiversity that exists there. This paper analyzes the situation you are in the stream of Vestia, located in Selvíria-Ms, from descriptive landscape analysis and compare them with information from the Landsat 5 / TM satellite, so that it can complete the reliability of technical photo interpretation. From the listing of both data, which has been found is that the description from satellite images can serve as an aid for field work, but does not meet the needs of the description and analysis of it. Working in isolation, it is noticed that the spatial distribution of the images allows us to work in landscape as a whole, analyzing the elements that interact in the basin, but only from the fieldwork in the detailed description may occur.

KEYWORDS: Basin. Planning. Satellite image.

\section{IMPLICACIONES PARA EL USO DE IMÁGENES LANDSAT 5/TM IMAGINERÍA PREPARAR LA PLANIFICACIÓN EN LA CUENCA DEL ARROYO VESTIDO, SELVÍRIA-MS.}

\section{RESUMEN}

Se puede afirmar que el crecimiento económico siempre prevalecía antes de la utilización de los recursos naturales. Aunque limitados, estos son los recursos necesarios para alimentar el mercado cada vez más exigente, lo que priva de material cada vez más crudo para su uso en un proceso de producción en líneas capitalistas. Como consecuencia, los recursos se vuelven escasos y salvaje sienten su impacto afecta directamente a la biodiversidad que se encuentra allí. En este trabajo se analiza la situación en la que nos encontramos con el vestia corriente situada en Selvíria-MS, desde el análisis descriptivo del paisaje y los comparamos con la información del 5/TM imágenes Landsat de satélites para que se pueda completar el fiabilidad de las técnicas de interpretación de fotos. A partir de la catalogación de los dos datos, que se encontró es que la descripción de las imágenes de satélite puede servir como una ayuda para el trabajo de campo, pero que no satisface las necesidades de descripción y análisis de la misma. Trabajar de forma aislada, nos encontramos con que la distribución espacial de las imágenes nos permite trabajar juntos paisaje, el análisis de los elementos que interactúan en el cuenco, pero fue sólo a partir del trabajo de campo en la descripción detallada puede ocurrir.

PALABRAS-CLAVE: Cuenca. Planificación. Imagen de satélite.

\section{INTRODUÇÃO}

Não se começa falando de bacia hidrográfica e como o meio urbano á degrada sem antes abordar suas causas e consequências. Pode-se afirmar que o crescimento econômico sempre prevaleceu perante a utilização dos recursos naturais. Apesar de 
limitados, são esses recursos os indispensáveis para abastecer o mercado cada vez mais exigente, retirando cada vez mais matéria prima para a utilização em um processo produtivo nos moldes capitalistas. Como consequência, os recursos tornamse escassos e o meio natural sente seu impacto de forma direta, afetando a biodiversidade ali existente.

O presente artigo não busca desvendar as justificativas para a utilização dos recursos, mas sim a forma errônea de utilização desses meios, escasseando ao ponto que muitos deles não se prolongarão para as próximas gerações. Esses casos se repetem como, entre tantas formas, pela devastação da biodiversidade, poluição dos rios e a inserção direta da agropecuária, mas, principalmente, pelo crescimento desenfreado das cidades, comprometendo o equilíbrio natural de toda a área.

O município de Selvíria, localizado no estado do Mato Grosso do Sul não se encontra em posição diferente. Apesar de ter uma história de resistência, a agropecuária e a plantação de eucalipto avançam continuamente, substituindo ou degradando o meio ambiente que ali existia.

Contudo, na teoria geral dos sistemas de Bertalanffy (1977), o autor salienta que o ambiente deve ser compreendido de forma complexa, sendo que cada elemento é caracterizado por sua função única, interagindo de forma direta ou indireta com todo o sistema a sua volta. Partindo dessa premissa, a Bacia Hidrográfica do Córrego da Véstia se situa na seguinte forma: Bacia Hidrográfica do Rio Paraná Sistema; Bacia Hidrográfica do Rio Sucuriú - Subsistema; Bacia Hidrográfica do Córrego da Véstia - Parte Componente.

Contudo, Selvíria é um município recente quando comparados com outros do mesmo estado. Isso se torna um ponto positivo para estudos de impacto ambiental, já que a utilização de imagens multitemporais podem oferecer informações inimagináveis até então. Mas até onde essas informações são válidas?

Desta maneira, o presente trabalho procura analisar a situação em que se encontra o Córrego da Véstia, localizada no município de Selvíria-Ms, a partir de análise descritiva da paisagem e compará-las com informações provenientes do 
satélite LANDSAT5/TM, para que assim possa concluir a confiabilidade das técnicas foto interpretativas.

\section{REFERENCIAL TEÓRICO}

Com o crescente anseio em conhecer os processos naturais atuantes no passado e a inserção e adaptação do homem na paisagem até então atual, a tendência é que se deixe de lado algo que nos é próximo: o hoje. A produção acadêmica também traz essa vontade à tona no momento em que artigos científicos devem ser disseminados em número cada vez maiores e com maior rapidez. Esses trabalhos não raros às vezes geram produtos fracos ou muitas vezes falsos, prejudicando diretamente quem os utiliza.

Mesmo Christofoletti (1974) já afirmava que os estudos relacionados aos canais fluviais possuem informações relevantes, muitas vezes levando a compreensão e elucidação de questões morfológicas em que, a partir de processos morfogênicos, torna-se um dos mais ativos na esculturação da paisagem terrestre. 0 que vem sucedendo são a ausência da confirmação desses dados in situ localizados em alguns trabalhos nas mais diversas áreas.

As geotecnologias, em especial o sensoriamento remoto, apresentam ferramentas de suma importância para a análise ambiental, tais como as técnicas de extração de informações via fotointerpretação. Rosa (1992) salienta qualquer trabalho que utilize fotografias aéreas ou imagens de satélite, devem ter, como parte do trabalho, a coleta de dados realizados em trabalhos de campo e a interpretação visual das imagens a serem trabalhadas.

Partindo dessa premissa, o que se tem presenciado é o distanciamento da paisagem a ser analisada, do real, cada vez mais, como consequência do uso excessivo das imagens de satélite. O que deve ser pensado a respeito desses dados é até onde temos o avanço e o retrocesso das informações. Apesar das técnicas de sensoriamento remoto e geoprocessamento serem uma ferramenta fundamental e indispensável para situar e analisar o espaço geográfico deve-se refletir qual é o limite 
em que a persistência desses dados interpretativos e os em campo se completa, se dialogam perante o espaço físico real.

\section{HISTÓRIA}

Foi encontrado no website da Prefeitura Municipal de Selvíria (2014) um breve apontamento sobre o rápido desenvolvimento em que a cidade passou em sua jornada. Nele, se faz referência ao ano de 1963, onde as obras da Usina Hidrelétrica (UHE) de Ilha Solteira, localizada no rio Paraná, traria grande afluxo de trabalhadores de todos os cantos, formando em pouco tempo uma cidade dormitório com aproximadamente 30 mil pessoas do lado paulista.

Contudo, ao mesmo tempo, a própria empresa estimulava o loteamento de terras que era feito do outro lado do rio, no estado do Mato Grosso do Sul, diminuindo desta forma o contingente de trabalhadores morando em suas instalações e minimizando problemas com habitação. A cidade nasceu com o loteamento das terras do fazendeiro João Selvírio de Souza, que, com o lucro da venda das terras, investiu no que seria posteriormente chamado de município de Selvíria. Com a finalização das obras da UHE, parte da mão de obra que se encontrava ali migrou junto com a construtora, levando assim os recursos da vila que seguia a sombra da CESP. Apesar do descaso da empreiteira, Selvíria em pouco tempo passou de distrito de Três Lagoas-MS, em 1976, para a situação de município, em 1980, mantendo-se firme desde a sua fundação.

Apesar das histórias de luta do município, Selvíria não é uma exceção à regra. Com a expansão do município e a demanda do desenvolvimento econômico local, alguns de seus córregos foram diretamente afetados pelo descuido gerado pelo desinteresse da preservação, como é o caso do Córrego da Véstia, localizado entre o município de Selvíria e o bairro Véstia, ambos no Mato Grosso do Sul.

\section{OBJETIVOS}


Deve-se pensar nos estudos de bacia hidrográfica como um sistema de interrelações e interdependência, formado a partir de seus constituintes e cada uma de suas peculiaridades, sendo as partes que formam o todo.

É de compreensão nos estudos ambientais que bacias hidrográficas formam um conjunto de elementos, bióticos e abióticos, que apesar de diferentes, possui uma finalidade, concebendo desta maneira seu equilíbrio natural.

$\mathrm{O}$ trabalho tem como objetivo subsidiar e confirmar se há validade a análise feita via imagens orbitais via imagens LANDSAT5/TM, de resolução espacial de 30m, sem a confirmação do meio físico, elaborado apenas a partir da fotointerpretação do Córrego da Véstia, validando a necessidade de trabalho de campo para a busca do resultado almejado.

\section{METODOLOGIA}

O Córrego da Véstia vem sendo tomado não apenas pela ocupação municipal, mas por toda a falta de cautela ao planejar, ocupar e a preservar a área em questão, tomando certo intervalo do equilíbrio ambiental em que se encontrava antes da sua tomada.

Partindo dessa premissa, o presente estudo pretende verificar até onde essas informações são válidas. Para isso, o trabalho se desenvolverá em três etapas.

Durante a primeira etapa, será elaborada uma análise foto interpretativa a partir de imagens mais recentes do satélite LANDSAT5/TM, órbita 223 ponto 074, utilizando a composição rgb453. Fitz (2008) salienta que a fotointerpretação é o eixo mais próximo em que liga o sensoriamento remoto com as geotecnologias.

A segunda etapa será semelhante à etapa anterior, contudo, serão utilizadas imagens de tempos pretéritos do Córrego da Véstia proveniente do satélite LANDSA5/TM, órbita 223 PONTO 074, também utilizando a composição rgb453. Ambas as imagens de satélite passarão por georreferenciamento e recorte da área de interesse. 
Na terceira etapa será feito um trabalho de campo para a confirmação de todas as informações, sanando todas as dúvidas que possam ser surgidas durante a fotointerpretação. Ainda em campo, serão utilizados como material uma máquina fotográfica para aquisição de registros, um aparelho de GPS para aquisição de coordenadas de latitude e longitude, viabilizando a confirmação das informações obtidas via imagens orbitais e prancheta de campo, passível de anotação das duas informações, tal como a descrição e análise da paisagem para que, desta forma, seja possível associar todas as informações possíveis, sanando possíveis dúvidas.

Conforme o desenvolvimento das três etapas espera-se determinar até onde se pode avançar e/ou retroceder nos estudos ambientais utilizando apenas imagens de satélite, e se esses dados se complementam ou somente se distanciam conforme a paisagem apresentada na bacia hidrográfica do Córrego da Véstia.

\section{RESULTADOS}

Para dar início ao método de descrição da paisagem, a delimitação da bacia hidrográfica do Córrego da Véstia foi feita a partir de modo automático a partir de imagens SRTM, disponíveis no site da EMBRAPA, e refinadas no software ArcGIS ${ }^{\circledR}$. As imagens LANDSAT5/TM também passaram por tratamento, sendo as mesmas georreferenciadas e recortadas conforme a área estudada. Com o tratamento finalizado, foi gerado um mapa de localização da área de estudo conforme a figura 1 . 
Figura 1: Localização da área de estudo a partir da imagem LANDSAT5/TM datado em $07 / 08 / 2011$.

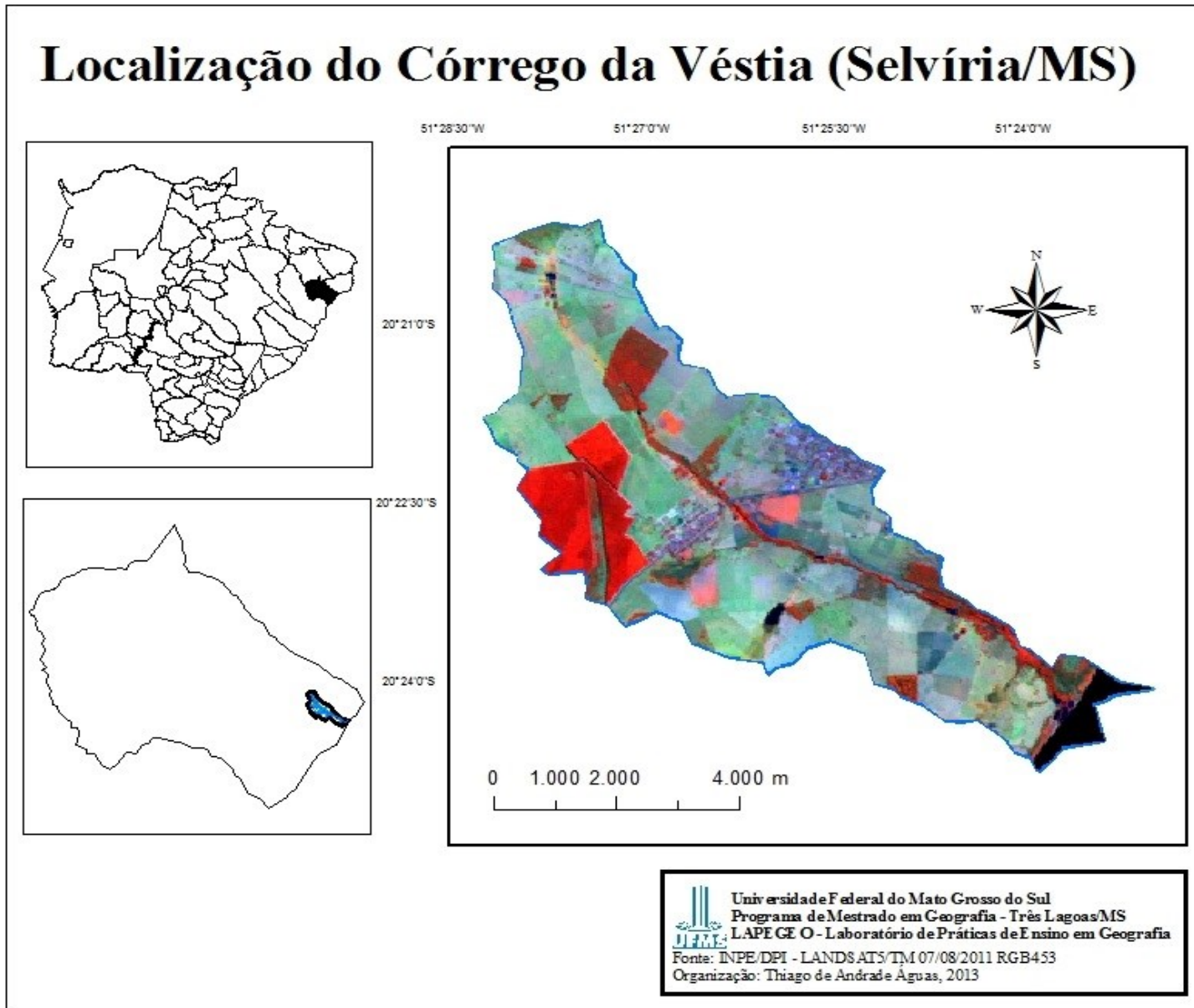

Fonte: INPE/DPI

Organização: Thiago de Andrade Águas, 2013.

Como o presente artigo propõe fazer uma análise dos avanços antrópicos na bacia hidrográfica via interpretação de imagem, a composição das bandas RGB453 se adequou melhor devido a fácil visualização do solo em preparo, agricultura perene e temporária, áreas úmidas, etc. Vale lembrar que a resolução espacial do satélite é de $30 \mathrm{~m}$, ou seja, cada pixel formador da imagem contém $30 \times 30 \mathrm{~m}$ de resolução espacial. Para a elaboração do trabalho, foi imprescindível a descrição detalhada da área em três etapas. 
Rosa (1992) compreende que a interpretação de imagens de orbitais para a utilização de descrever o uso da terra é importante, pois é o início da compreensão dos padrões de organização do espaço em si. Quanto mais registro se tem da área, mais facilmente essa interpretação será feita, e o sensoriamento remoto dá essa possibilidade de interagir com outros dados, sendo de outras épocas ou outras fontes, salienta o autor.

Para Rosa (1992), o termo uso e ocupação da terra demonstram a forma em que o espaço está sendo ocupado e que sua compreensão é importante, pois a desorganização antrópica gera desequilíbrios ambientais.

$\mathrm{Na}$ primeira etapa do estudo, a descrição da imagem do satélite LANDSAT5/TM em que foi constado que o Córrego da Véstia se encontrava em bom estado de preservação na data de 07 de Agosto de 2011. Apesar do avanço da cidade perante o mesmo, sua nascente continua em bom estado de conservação e, apesar da predominância de pastagem e plantações de eucalipto na região, as áreas de preservação continuavam sendo respeitada.

A porção sudoeste da nascente apresentou indício de vegetação, mas sem a confirmação do que poderia ser devido a diferente forma de resposta espectral do mesmo, sem contar que a forma geométrica da imagem apresentou algo de inserção antrópica. O que se percebe no geral é que a predominância na região é o agronegócio devido à vegetação pouco representativa e apresentando lugares com solo exposto. Também foi constatada a baixa representatividade do município na bacia hidrográfica, sendo como predominante a zona rural.

Com a descrição prévia da bacia a partir da imagem LANDSAT5/TM datada em 08 de julho de 2011, a segunda etapa do trabalho é iniciada, dando primórdio à descrição da imagem de 12 de outubro de 1984. A mesma é representada na figura 2. 
Figura 2: Localização da área de estudo a partir da imagem LANDSAT5/TM na data de 12/08/1984.

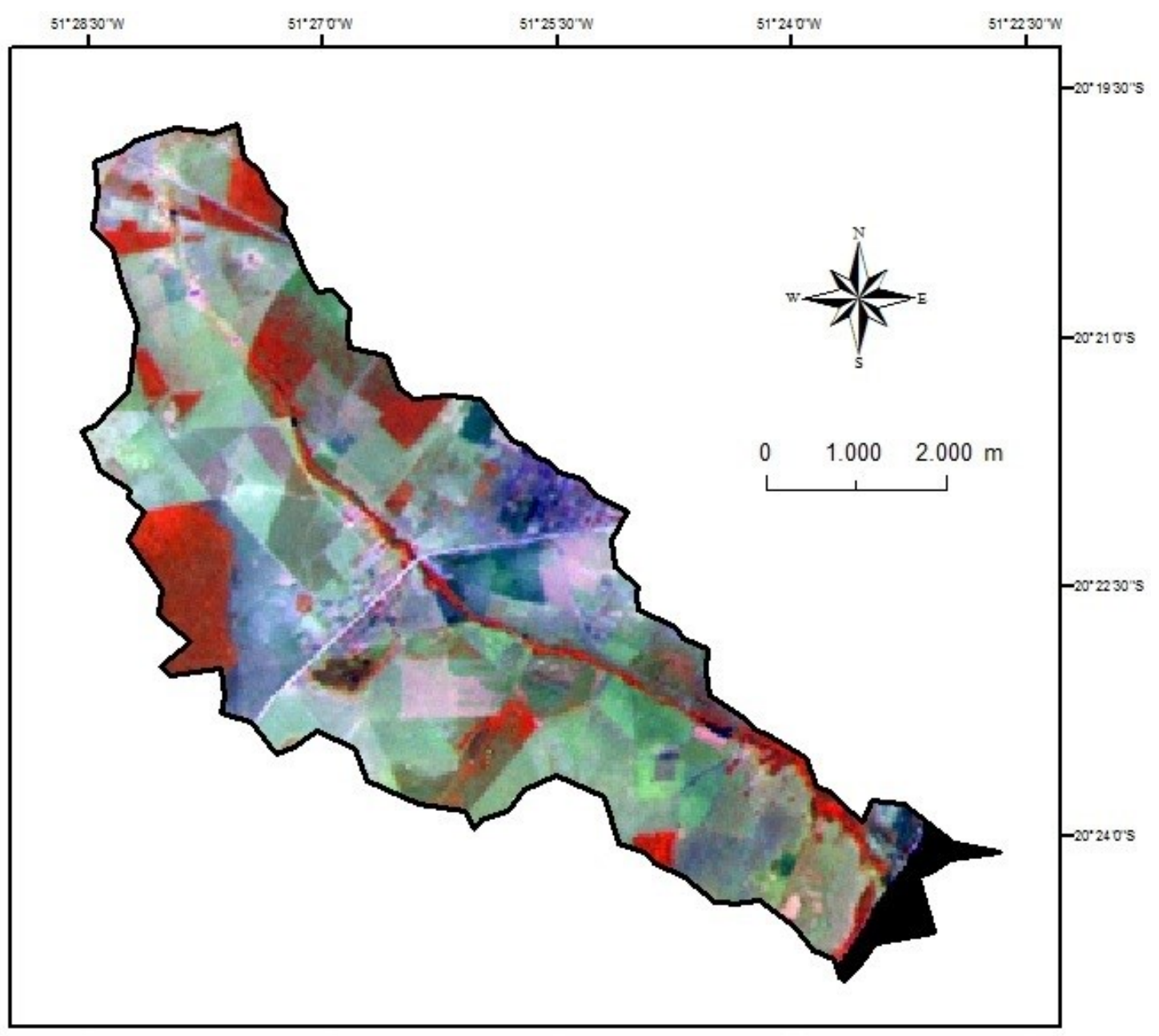

Fonte: INPE/DPI

Organização: Thiago de Andrade Águas, 2013.

A segunda etapa do trabalho demonstra como o crescimento da cidade foi efetivo em pouco tempo, contudo, a devastação e o avanço ocorrido na bacia não foram diferentes. A porção norte, sudeste e sudoeste da nascente apresentam algum tipo de vegetação, o que dá a entender por consequência antrópica, já que as mesmas possuem formas geométricas. A parte sul do município de Selvíria ainda 
estava em sua fase de loteamento, tendo em vista que a resposta espectral da área representa solo exposto. Também é possível notar que a rodovia já existia naquela região, caracterizando um desenvolvimento local e degradação ambiental. Em relação às áreas de preservação permanente, nota-se que a imagem mais recente está mais preservada, na qual a justificativa é desconhecida até então.

Já em campo, na etapa três, foi elaborada a descrição de cinco pontos no dia 05 de Junho de 2012, dos quais podem ser visualizados na figura 3, representada na imagem de alta resolução do Google Earth. Os pontos não foram escolhidos aleatoriamente. A possibilidade de entrar nas fazendas para encontrar o córrego foi uma dificuldade encontrada. Foi escolhido trabalhar com a parte superior do córrego da Véstia devido à influência da rodovia, facilitando desta forma a descrição durante o percurso sentido nascente. Também se optou em não divulgar sua localização exata, evitando assim eventuais problemas. A análise descritiva desses pontos foi demonstrada um a um, como se segue.

Figura 3: Localização dos pontos descritivos no trabalho de campo e as respectivas fotografias da área em questão.

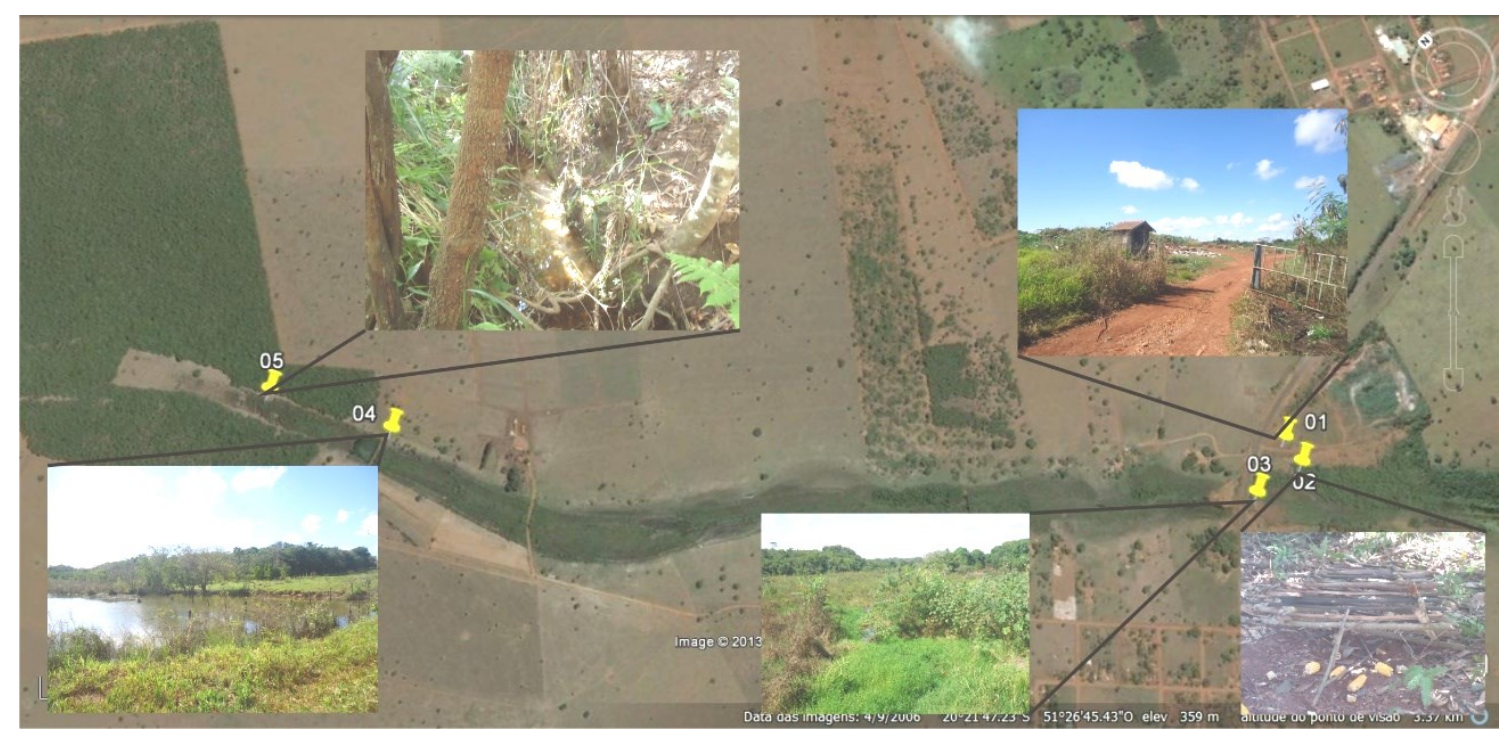

Fonte: Google Earth

Organização: Thiago de Andrade Águas, 2013. 
- Ponto um - 325m - Encontra-se nas proximidades de um lixão, consequência da expansão urbana. A predominância da vegetação ali encontrada é exótica, presenciando grandes concentrações de mamonas e na margem do córrego vegetação de médio e grande porte.

- Ponto dois - 324m - Presença de vegetação de médio e grande porte, com predominância de vegetação rasteira. Na vertente foi encontrado determinada área que possivelmente já fez parte do curso d'água. Também foi encontradas armadilhas e clareiras naquele local, indicando ações ilegais na área.

- Ponto três - 349m - Primeiro contato com o curso d'água do Córrego da Véstia. A vegetação predominante encontrada é de médio porte, mas o que chamou atenção foi à presença da braquiária d'água. De caráter exótico, possui nódulos que, ao tocar o solo, rebrotam. Esse tipo de vegetação produz substâncias que intoxicam o gado quando ingerido por muito tempo, mas também inviabiliza a vegetação aquática e o crescimento de outro tipo de fauna no entorno. Foram catalogados o capim rabo de burro e a pindaíba do brejo, representando a transição entre a área úmida e a seca, e a Embaúba, indicando clareiras e áreas de aterro.

- $\quad$ Ponto quatro - 349m - Presença de um açude na fazenda. Foi encontrado organossolo e grande quantidade de pau pombo. Há forte influência de vegetação exótica devido ao revolvimento da terra para o pasto. Também se deu falta de líquens, indicando que houve alguma enchente ou fogo próximo ao açude.

- Ponto cinco - 355m - Primeiro contato com a nascente. Possui o seu canal encaixado e, como consequência do lençol baixo, é bastante propícia a espécies lenhosas.

A partir da catalogação de ambos os dados, o que foi constatado é que a descrição a partir de imagens orbitais pode servir de auxílio para trabalhos de campo, mas não supre as necessidades da descrição e análise do mesmo.

Um problema encontrado na primeira e segunda etapa foi que a qualidade da imagem dificultou a fotointerpretação. Isso ocorreu, pois a imagem LANDSAT5/TM possui baixa resolução espacial, juntando elementos distintos em um só pixel de 
30x30m, como ocorreu ao confundir as áreas de APP com a braquiária d'água. Contudo, esses problemas podem ser comuns no momento em que essas imagens são disponibilizadas gratuitamente e amplamente utilizadas. Esses erros podem ser minimizados com imagens de alta resolução.

Podem-se concluir a partir de ambas as análises é que a fotointerpretação de imagem não pode ser trabalhada isoladamente, assim como os dados de campo não suprem todas as necessidades para estudos de bacias hidrográficas. Ambas trazem informações únicas e peculiares ao ambiente a ser estudado. Infelizmente informações pretéritas em campo só podem ser resgatadas a partir de entrevistas ou acervo histórico. Todas as informações disponíveis para análise e planejamento de estudos ambientais são válidas, desde que verdadeiros e comprometidos.

\section{CONSIDERAÇÕES FINAIS}

Com a realização desse artigo comparativo, pode-se notar que a informação dada via imagens orbitais não oferecem todos os recursos necessários para a interpretação do meio físico, assim como o trabalho de campo não supre todas as informações necessárias devido à dificuldade de deslocamento em longas áreas. Ao realizar um trabalho descritivo a partir de imagens LANDSAT5/TM sobre a bacia hidrográfica do Córrego da Véstia notou-se a dificuldade em entender todos os elementos visíveis ao mesmo tempo em que, em campo, não seria possível entender a dimensão do meio sem as informações dadas pelas imagens. Deve-se pensar que no planejamento de área, essas duas informações devem sempre vir a se complementar e nunca a subtrair. Pois são as pequenas partes da natureza que se completam, formando o meio físico geográfico.

\section{REFERÊNCIAS}


Borsato, F. H. \& Martoni, A. M. Estudo da fisiografia das bacias hidrográficas urbanas no Município de Maringá, Estado do Paraná. Acta Scientiarum. Human and Social Sciences Maringá, v. 26, n. 2, p. 273-285, 2004.

Bertalanffy, L. V. Teoria Geral dos Sistemas. Petrópolis: Editora Vozes, 1977.

Christofoletti, Antônio, 1936-Geomorfologia. São Paulo, Edgard Blücher, Ed. Da Universidade de São Paulo, 1974.

Fitz, Paulo Roberto. Geoprocessamento sem complicação. Paulo Roberto Fitz. -São Paulo: Oficina de Textos, 2008.

Jensen, John R., 1949-Sensoriamento remoto do ambiente: uma perspectiva em recursos terrestres / John R. Jensen; tradução José Carlos Neves Epiphanio (coordenador)... [et al.]. - São José dos Campos, SP: Parêntese, 2009.

Prefeitura Municipal de Selvíria. Selvíria e sua História. Disponível em http://www.selviria.ms.gov.br/. Acesso em: 23 de julho/2014.

Rosa, Roberto. Introdução ao sensoriamento remoto. $2^{a}$ ed. rev. Uberlândia, Ed. da Universidade Federal de Uberlândia, 1992. 